\title{
Childhood Pilocytic Astrocytoma
}

National Cancer Institute

\section{Source}

National Cancer Institute. Childhood Pilocytic Astrocytoma. NCI Thesaurus. Code C4048.

A pilocytic astrocytoma that occurs during childhood. 